it with an increased range in the passage between Gaspé and Anticosti, and from there pursues its way with ever-increasing height up the St. Lawrence to Quebec. The progress of this tidal wave has been traced to the existence of a deep channel which crosses the whole extent of the Gulf from Cabot Strait to the passage between Gaspé and Anticosti, and thence up the St. Lawrence nearly to Saquenay. This channel extends a distance of 500 miles, with an average width of 35 miles and a continuous depth of i 50 fathoms.

For the purpose of ascertaining the nature and velocities of the currents, the steamer used was moored with a wire rope hawser, provided with an accumulator, to prevent sudden jerks and strains. This accumulator consisted of a series of sixty rubber discs, five inches diameter, making a total length of twelve feet, which was reduced to eight feet eight inches under the greatest compression. Two kinds of current meters were used : one having small buckets revolving horizontally, on the same principle as an anemometer; and the other of a fan, similar to a screw propeller, revolving in a vertical plane. The former was found to be best for sea work, as it was least affected by the vertical motion of the vessel due to waves. The latter was found to be liable to head up or down as the vessel rolled, and so give an exaggerated record. Both kinds were worked by electricity. The surface currents were taken at a uniform depth of eighteen feet, which was well clear of the keel of the steamer. The meter was allowed to run for half an hour at this depth, then lowered to the desired depth for an hour, and then again run for half an hour at the eighteen feet. At a depth of ten fathoms the Gaspé current was sometimes found to be stronger than at the surface, but usually the velocity decreased regularly with the depth. At twenty fathoms it was only 50 per cent. of the surface velocity; and at thirty fathoms, 20 per cent. The greatest velocity was $2.8 \mathrm{I}$ knots. The current fluctuated with the rise and fall of the tide, decreasing during the rise, and increasing during the fall. The constant outward current from the Gulf was found to have a width of fourteen miles, and a depth of forty fathoms near the Gaspé coast, with a surface velocity of from I'IO to $2 \cdot 8 \mathrm{I}$ knots. The temperature in July was found to range from $53^{\circ}$ at the surface to $33^{\circ}$ at thirty fathoms; and $32^{\circ}$ at fifty fathoms. In the Gaspé region and in Cabo Strait the coldest water forms a layer between the depth of thirty and fifty fathoms, and, while the surface water rises in temperature during the season, no appreciable variation was found from June to September at a depth of fifty fathoms.

The density of the water was ascertained as affording an indication of the quantity of fresh water coming down the St. Law rence. In the Strait of Belle Isle and Cabot Strait the density of the surface water ranges from I $\cdot 0233$ to $\mathrm{I}^{\circ} \mathrm{0} 245$, the same as in the Atlantic. On the western side of Cabot Strait, the out flowing water, which occupies a width of about ten miles, has a density of $\mathrm{I} \cdot 0220$ to $\mathrm{I} \cdot 0235$ at the surface. In the Gaspé region the average density for a width of fourteen miles, and between the surface and ten fathoms, was I.02195: and to a depth of forty fathoms, was $x^{\circ} 02368$. The density of the water is disturbed by currents due to wind. Thus during three days, when the wind from the S.S.W. averaged twenty miles an hour, the density contours were displaced to the northward about nineteen miles at the surface, fifteen miles at ten fathoms, and nine miles at twenty fathoms.

The completion of the survey is expected to occupy another three or four years.

\section{AGRICULTURAL EXPERIMENTS IN PLOTS AND POTS.}

IN a recent number of the Agricultural Gazette of New South Wales (vol. vii. p. 663) there is an article by Mr. N. A. Cobb, written at the request of the Minister for Agriculture, upon the methods employed for, experiments with crops and manures. It appears that field experiments are being carried out to a considerable extent by the farmers of the country, but that the results are to a large extent untrustworthy and misleading, owing to innumerable sources of error which the experimenters have failed to perceive and guard against. Science is thus brought into ill repute, doubt is thrown on established truths, and progress hindered. The evidence brought forward goes far to show that this is a true indictment. When, however, the author goes a step further, and speaks of field experiments as almost essentially untrust worthy, we cannot agree with him. The sources of error which he mentions may all be avoided by judicious management, if only the experimenter will guard against them at the commencement of his work, and superintend his operations with proper care.

Inequalities of soil are one of the worst erils in field experiments; the investigator frequently remains unconscious of them, the difference in the results being credited to the effect of the manures, \&c. It is very rare for proper precautions to be taken against this evil, for the simple reason that these precautions imply delay, and the experimenter is generally in a hurry to obtain results. If, for instance, the comparative effect of different manures on barley is to be ascertained, or the comparative yield of different varieties of seed, the only basis for an accurate trial is to divide the field into the required plots, then sow the whole field with a uniform barley seed, without any manure, and weigh separately the produce of each plot. If the crops obtained are equal, within the unavoidable errors of experiment, the field is one suitable for the purpose of the experiment ; if the crops are unequal, the field, or that portion of it in which the inequality occurs, is clearly unsuited for the purpose intended. It is not sufficient, as is often supposed, to inspect the field when under ordinary culture, and because of the apparent evenness of the crop, to pronounce it fit for use ; for natural inequalities of soil may not appear in a well-manured field, although plainly manifested when the supply of manure ceases.

The errors due to inequalities of the soil in one series of trials may, of course, be neutralised by making many series of trials, and substantial accuracy may be gained by simply regarding the mean results obtained ; but if a field is really unequal in fertility, no ordinary arrangement of duplicate plots will suffice to ensure an accurate result. If the same experiment is repeated throughout a wide district, as is often now done in County Council experiments, it may be quite misleading to take the mean of all the results as expressing the truth for the whole district. We must not bring into the mean the results obtained in different soils and climates, unless, indeed, our aim is to procure general statistics which are of no value for any particular place. Basic slag and superphosphate will compare quite differently upon a clay and upon a chalky soil ; nitrate of soda and sulphate of ammonia will compare differently on dry and wet soils. To take the mean of experiments made under such different conditions is simply to misinform every farmer in the district; yet public money is continually wasted in this way.

Mr. Cobb points out that the effect of inequality in the soil may be obviated by substituting rows for square plots. This is true, and the point is well worthy of attention; the suggestion is not, however, novel. In a comparison of basic slag and superphosphate for turnips, conducted by the writer at Rothamsted in I 886, the slag and turnip seed were sown by drill on the top of two ridges down the whole length of the field, and on the return of the drill an equal number of ridges by the side of the first were left unsown. When the sowing of the slag was completed, the same drill sowed superphosphate and turnip seed in all the vacant spaces. There were thus throughout the field two rows of turnips with slag, side by side of two rows of turnips with superphosphate, the repetition occurring many times over. This plan was suggested by Sir John Lawes. This is, for many experiments, a good mode of work, but its use is practically limited to those crops and manures which can be sown by drill unfortunately, drills are not satisfactory machines for evenly distributing given weights of manure over given areas.

$\mathrm{Mr}$. Cobb next passes to the pot system of experiment : he describes the work at the Darmstadt Experiment Station, with its IOoO pots, and suggests that work on this system should be commenced in Australia.

There is no doubt that for solving certain questions the pot system, when carried out with scrupulous accuracy, is far superior to any other. If we wish to know what is the com. parative value to any plant of various nitrogenous manures under the most favourable conditions of supply and use, we arrive at this fact only by pot experiments. The produce obtained per unit of nitrogen in the pot will not, however, necessarily be the produce obtained in the field; and the relative value of differen manures, as shown in the pot, will only by mere chance appear in the field, where, in fact, it will be found to vary every year. The essential difference between the two systems is due to the fact that the field results are largely influenced by the season, and especially by the amount of rain, and the quantity of water percolating through the soil; while the pot cultures are carefully protected from such vicissitudes. If, then, the farmer 
wants to know how nitrate of soda, sulphate of ammonia, and shoddy, compare in his own land and climate, the only way of ascertaining the fact is by field experiments repeated through many years, till the influence of an average season is ascertained.

R. W.

COLLIER Y EXPLOSIONS AND COAL-DUST.

$A \mathrm{~T}$ a meeting of the Physical and Chemical Section of the Bristol Naturalist Society, on January 26; a paper was read, by Mr. Donald M. D. Stuart, upon "The Chemistry of Colliery Explosions due to Gases derived from Coal-dust," in which the researches of Faraday, Verpilleux, Vital, Marreco, Mallard, Le Chatelier, and others were given, and attention was drawn to the points they emphasised. Faraday observed in his report upon the Haswell Colliery explosion: "There is every reason to believe that much coal-gas was made from the coaldust in the very air itself, by the flame of the fire-damp ; . . and that much of the carbon in this dust remained unburnt only for want of oxygen." M. Vital concluded that-."Very fine coal-dust rich in inflammable constituents, will take fire when raised by an explosion, and that portions are successfully decomposed, yielding explosive mixtures with air, whereby the fire is carried along." Marreco remarked-" The coal-dust is in part submitted to destructive distillation"; and Mallard and Le Chatelier found that gaseous matters were evolved from the coal-dust by the action of the fire-damp explosion. Mr. Stuart observed. These physicists and chemists found that the coaldust did undergo dry distillation while in atmospheric suspension in a mine passage, after the originating explosion; and the educts added to the explosive effects. He had carefully observed the effects of explosions not only at the point of origin, but throughout the field of the disturbances, and found Faraday's hypothesis of the dry distillation of coal-dust essential to account for the phenomena observed through thousands of yards of mine passages. He observed that the disruptive effects of an explosion of methane and air were necessarily limited to the immediate vicinity of the explosive mixture; but the disruptions beyond and to remote distances required an explosive agent coextensive in distribution, and this agent was coal-dust.

The fields of disturbance exhibited the effects of gas-explosion at separate points of space, with intervals of no explosion but of heat, partial combustion, and dissociation; requiring, for explanation, a chain of chemical changes liberating quantities of heat, and accumulating an explosive mixture at the place of explosion. The question arose whether a given volume of air could hold in suspension, as dust, a sufficient weight of coal to give, by its resolution into gas, more gas than the given volume of air was capable of burning or exploding; and investigation showed that the coal yielded a quantity of combustible gases, not less than one half the volume of the air in which it was suspended. In these conditions there could be only partial combustion, until a place was reached where the mine passage emerged into a capacious chamber in which the unconsumed gas found sufficient atmospheric oxygen, and was exploded by the flame in the partial combustion referred to. The disruptive effects were located in places of large air capacity in the paths of coal-dust.

At the point of origin, the coal-dust was reduced to cuke, the residue of dry distillation; and this phenomenon was of frequent recurrence in the paths of the propagated explosions. Amorphous carbon was found universally deposited in the field of explosions, chiefly upon the vertical side-walls; it was alsc in copious suspension in the stagnant atmosphere in the pas. sages, and the effluent gases at the shafts. Combustible bodies, as timber, cotton fabrics, and candles, forming obstructions in the paths of coal-dust and between the explosions, were not consumed or burned. The bodies of the victims in these in tervals were blistered to various degrees ; the cotton fabrics retained their external form, but had been deprived of their volatile matter, the candles had melted and run together, and the adjacent coal-dust and lumps of coal had undergone dry distillation. These effects upon the coal, men; calico, and candles disclose the fact that the atmospheric oxygen in the mine passages was not more than adequate to supply a portion of the educts of the coal undergoing distillation; consequently there was no oxygen available for the chemical requirements of other combustible bodies, as timber, clothes, cotton fabrics, and candles.

$$
\text { NO. :434, VOL. 55] }
$$

The chemical changes in the intervals from explosion to explosion caused considerable diminution in the atmospheric pressure, indicating a very small production of permanent gases, and the employment of the atmospheric oxygen to form readily condensible gas.

The explosions at the non-gaseous Camerton and Timsbury Collieries were originated by the heat in the products of the exploded blasting powder. The temperature of fired powder of a similar composition was determined by Abel and Noble at $1800^{\circ}$ to $2000^{\circ} \mathrm{C}$.; the products, therefore, struck the coal-dust in the immediate vicinity while at an exalted temperature, certainly higher than that of the gas retort, which is below $1000^{\circ} \mathrm{C}$. The educts of the coal-dust would consequently be similar to ordinary illuminating gas. The composition of London gas is given (by Frankland) at $5 \mathrm{I}^{\cdot} 24$ per cent. free hydrogen, 38.84 per cent. gaseous hydrocarbons, and some other bodies.

Upon the foregoing and other data, Mr. Stuart advanced the following rationale of a colliery explosion :-The educts of the coal are in excess of the relative combination volumes of atmospheric oxygen present; therefore the large proportion of nascent free hydrogen present, seizes the principal part of the oxygen, liberating heat in the combination. Some of the hydrocarbons obtain the remaining oxygen, causing a limited combustion, as in the preparation of diamond black, disengaging more heat, and placing amorphous carbon in suspension. At the temperature of burning hydrogen, the hydrocarbons that have not undergone change, for want of oxygen, are dissociated, placing more amorphous carbon in suspension, and yielding free hydrogen for disruptive effects.

The heat in the products of the exploded powder, therefore, instituted a series of chemical actions in the coal-dust, in which large quantities of heat were disengaged, and free hydrogen placed at disposal for disruptive action. This series is regeneracive by virtue of the heat liberated, which instituted a similar series in the adjacent coal-dust; and these activities are of constant and similar reproduction along the paths of coal-dust until a place is reached, which supplies a large quantity of atmo. spheric oxygen, in which the accumulated hydrogen diffuses, and the mixture is ignited by the flame in the partial combustion, causing an explosion. This explosion liberates more heat, and re-establishes a similar chain of chemical changes in the coaldust beyond, closing in a second explosion at the next abnormal supply of air, and propagation proceeds along each path of coaldust so long as adequate oxygen is available, and wet surfaces do not intervene to reduce the temperature below the point at which the coal undergoing distillation yields sufficient free hydrogen to supply by its oxidation enough heat to make the actions continuous. The paper was illustrated with limelight slides, and was followed by an interesting discussion. Upon the motion of the President, Mr. Stuart was cordially thanked for his paper.

\section{A NEW DIPHTHERIA ANTITOXIN.}

A RECENT number of the Archives des Sciences Biologiques, issued by the Imperial Institute of Experimental Medicine in St. Petersburg, contains a highly important communication from Dr. Smirnow, on a new method of obtaining a diphtheria antitoxin of great therapeutic value. For the last three years Dr. Smirnow has been working on this subject, and the present memoir places experiments, which before were only in a tentative stage, on what now appears to be a sound and practical basis.

As is well known, the preparation of curative diphtheria serum involves not only great expense, but also a great deal of time; the raising of a horse's serum to the requisite pitch of immunising properties requiring many weeks. Dr. Smirnow has been endeavouring to produce an antitoxin, the preparation of which is less costly and less cumbersome. The method adopted was that of electrolysis, and in the first instance ordinary serum was electrolysed; but as this led to nothing, virulent diphtheria broth cultures were substituted for serum, and the results obtained were highly encouraging. These electrolysed cultures were found to contain an antitoxin of great efficacy, and, even when employed in smaller quantities than the therapeutic serum, it entirely protected animals from the effects of diphtheria poison. "Le traitement par cette antitoxine marche d'une manière remarquablement satisfaisante: malgré les périodes les plus avancées de la maladie, il suffit d'un demi 